Binghamton University

The Open Repository @ Binghamton (The ORB)

\title{
$5-2014$
}

\section{Brief Prenatal Ethanol Exposure Alters Behavioral Sensitivity to the Kappa Opioid Receptor Agonist (U62,066E) and Antagonist (Nor-BNI) and Reduces Kappa Opioid Receptor Expression}

\author{
Michael E. Nizhnikov \\ Southern Connecticut State University \\ Ricardo M. Pautassi \\ Jenna M. Carter \\ Justine Landin \\ Elena Varlinskaya \\ Binghamton University--SUNY
}

See next page for additional authors

Follow this and additional works at: https://orb.binghamton.edu/psych_fac

Part of the Psychology Commons

\section{Recommended Citation}

Nizhnikov, Michael E.; Pautassi, Ricardo M.; Carter, Jenna M.; Landin, Justine; Varlinskaya, Elena; Bordner, Kelly; Werner, David F.; and Spear, Norman E., "Brief Prenatal Ethanol Exposure Alters Behavioral Sensitivity to the Kappa Opioid Receptor Agonist (U62,066E) and Antagonist (Nor-BNI) and Reduces Kappa Opioid Receptor Expression" (2014). Psychology Faculty Scholarship. 4.

https://orb.binghamton.edu/psych_fac/4

This Article is brought to you for free and open access by the Psychology at The Open Repository @ Binghamton (The ORB). It has been accepted for inclusion in Psychology Faculty Scholarship by an authorized administrator of The Open Repository @ Binghamton (The ORB). For more information, please contact ORB@binghamton.edu. 
Authors

Michael E. Nizhnikov, Ricardo M. Pautassi, Jenna M. Carter, Justine Landin, Elena Varlinskaya, Kelly Bordner, David F. Werner, and Norman E. Spear 
DISCLAIMER: This is a post-print (ie draft post-refereeing) version of an article published in final form at the ACER

Full Citation is: Brief prenatal ethanol exposure alters behavioral sensitivity to the kappa opioid receptor agonist (U62,066E) and antagonist (Nor-BNI) and reduces kappa opioid receptor expression. Nizhnikov ME, Pautassi RM, Carter JM, Landin JD, Varlinskaya El, Bordner KA, Werner DF, Spear NE. Alcohol Clin Exp Res. 2014 Jun;38(6):1630-8. doi: 10.1111/acer.12416. Epub 2014 May 5. PMID: 24796820

The MS is uploaded to Research gate in accordance with the Journal's policies, as published in http://www.sherpa.ac.ukl. Final, published version of the article can be found at http://onlinelibrary.wiley.com/doi/10.1111/acer.12416/abstract 


\title{
'BRIEF PRENATAL ETHANOL EXPOSURE ALTERS BEHAVIORAL SENSITIVITY TO KAPPA AGONISTS AND ANTAGONISTS AND REDUCES KAPPA OPIOID RECEPTOR EXPRESSION.
}

\begin{abstract}
Abbreviated Title: Prenatal Ethanol Alters Kappa Opioid Expression
Michael E Nizhnikov ${ }^{1 *}$, Ricardo M. Pautassi ${ }^{2}$, Jenna M. Carter ${ }^{1}$, Justine D. Landin ${ }^{1}$, Elena I. Varlinskaya ${ }^{1}$, Kelly A. Bordner ${ }^{3}$, David F. Werner ${ }^{1}$, Norman E. Spear ${ }^{1}$.
\end{abstract}

1: Department of Psychology, Center for Development and Behavioral Neuroscience, Binghamton, NY 13902

2: Instituto Ferreyra (INIMEC - CONICET- UNC) and Faculty of Psychology, National University of Córdoba; Friuli 2434 - Cordoba - CP 5016

3: Department of Psychology, Southern Connecticut State University New Haven, CT 06515

* Corresponding Author: Science 4, Department of Psychology, PO Box 6000, Binghamton, NY 13902-6000

Pages: 24, Figures: 7, Words for Abstract: 236, Intro: 500, Discussion: 1346 Conflict of Interests: None

Aknowledgments: We would like to thank Elizabeth Paratore and Teri Tanenhaus for their technical help and in the preparation of the manuscript. This work was supported by 
grants, AA018164 and AA017823 (MEN), AA017823 (DFW), AA019367 (faculty recruitment of DFW), and AA011960, AA01309, and AA017823 (NES). 


\section{Abstract}

In the United States approximately $10-15 \%$ of women consume alcohol (ethanol) during pregnancy. Even low amounts of ethanol consumption during pregnancy can elicit long-term consequences. Prenatal experience with as few as 3 drinks has been associated with increase problem drinking in adulthood. Such effects are corroborated in rodents; however, the underlying neural adaptations contributing to this effect are not clear. In the current set of experiments, we investigated whether changes in ethanol responding following prenatal ethanol exposure involved kappa opioid receptor activation and expression.

Sprague-Dawley rats were prenatally exposed to low levels of alcohol $(1.0 \mathrm{~g} / \mathrm{kg})$ during late gestation (gestational day 17-20: GD17-20) via intragastric intubation of pregnant dams. Following birth, ethanol intake, kappa and mu opioid-induced place conditioning, and kappa opioid receptor expression in mesolimbic brain regions was assessed in infant rats (postnatal day 14-15: PD14-15) that were offspring of dams given ethanol, vehicle, or untreated, during pregnancy.

Animals exposed to prenatal alcohol drank more alcohol later in life and exhibited significant changes in the kappa opioid system. While control subjects found kappa opioid activation aversive, animals exposed to ethanol prenatally exhibited either no aversion or appetitive responding. Further analysis revealed that synaptosomal kappa opioid receptor expression was significantly decreased in brain areas implicated in responding to ethanol. Overall, this data suggests that prenatal ethanol affects kappa opioid function and expression and that these changes may be involved in increased drinking later in life. 


\section{Introduction}

Alcohol abuse is a worldwide concern affecting the lives of millions. While a large portion of the population drinks with little to no adverse consequences, a substantial number become dependent and abuse the drug with extremely adverse outcomes. Experience with alcohol in the womb or during infancy has been show to predispose individuals to problematic alcohol consumption later in life. Epidemiological studies confirm that humans exposed prenatally to a moderate amount of ethanol are at risk for alcohol abuse as adolescents and subsequently as adults (Alati et al., 2006, 2008; Baer et al., 1998, 2003; Yates et al., 1998).

Preclinical studies seem to confirm these epidemiological results. For example, studies have shown that rats exposed to 1.0 or $2.0 \mathrm{~g} / \mathrm{kg}$ ethanol on gestational days 17 20 (GD 17 - 20) exhibit enhanced ethanol intake in mid-infancy and adolescence (Arias \& Chotro 2005; Chotro et al., 2007; Chotro \& Arias 2003; Molina et al., 1999; Fabio et al., 2013) and learn conditioned preferences for doses of ethanol that untreated animals do not find reinforcing (Nizhnikov et al., 2006; Pautassi et al., 2012). Specifically, prenatal exposure to ethanol ( 1 or $2 \mathrm{~g} / \mathrm{kg}$ IG from $\mathrm{G} 17$ - 20) increases the range of ethanol doses that 3-hour-old and 14 day-old rat pups find reinforcing in comparison to untreated or water exposed controls (Nizhnikov et al., 2006, Pautassi et al., 2012).

A possible mechanism by which these effect might occur has been discussed by Abate and coworkers $(2001,2004)$. Their studies revealed that prenatal ethanol exposure can result in associative learning between the orosensory and the

postabsorptive, reinforcing effects of ethanol. Later re-exposure to the taste or odor of ethanol may trigger drug seeking and intake. Fabio et al. (2013) found that adolescent rats that had been exposed to ethanol during late gestation exhibited reduced baseline levels of c-fos activation in the prefrontal prelimbic area, an area involved in the 
extinction of learned associations. The mechanisms underlying this facilitative effect of prenatal ethanol on later ethanol intake remain however, largely unknown.

The endogenous opioid system plays a major role in ethanol reinforcement (Herz 1997; Vengeliene et al., 2008; Sommer et al., 2006; Méndez \& Morales-Mulia 2008). General blockade of the opioid system by administration of naltrexone disrupts ethanol intake and reinforcement in selected and unselected strains of rats and other species (Stromberg et al., 1998; Goodwin et al., 2001; Kato 2008; Nizhnikov et al., 2009; Barson et al., 2010), which has led to its application in treatment of alcoholism (Kranzler \& Van Kirk 2001; Pettinati \& Rabinowitz 2006). Antagonism of mu and delta opioid systems also inhibits both ethanol intake and reinforcement in adult and infant rats (Barson et al., 2010; Hyytiä \& Kiianmaa 2001; Lindholm et al., 2001; Mitchell et al., 2005 Nizhnikov et al., 2009; Pautassi et al., 2011). Moreover, administration of the general opioid antagonist naloxone to the pregnant, intoxicated dam inhibits the facilitative effect of prenatal ethanol on subsequent ethanol intake (Miranda-Morales et al., 2010).

The kappa opioid system has also been implicated in ethanol's motivational effects. Generally, kappa opioid receptors are present throughout the central nervous system (Atalli et al., 1990; Leslie \& Loughlin, 1992, 1993; Petrillo et al., 1987). Unlike the mu and delta opioid system, kappa activity appears to mediate the aversive properties of alcohol during infancy and adulthood in non-dependant rats (Land et al., 2009; Pillai et al., 1986; Pohorecky et al., 1989). For example, 14-day old rats found ethanol reinforcing, when assessed in conditioned place or taste preference, only after blockade of kappa opioid receptors (Pautassi et al., 2012b). Furthermore, selective kappa agonists attenuate ethanol intake in adult non-dependant rats while antagonists increase it (Mitchell et al., 2005; Logrip et al., 2009; Sandi et al., 1988; Matsuzawa et al., 1999; Jamensky \& Gianoulakis 1997). Intriguingly, animals which have been made ethanol dependant show the reverse response to kappa opioid manipulations, i.e. kappa 
antagonists reduce operant responding for and intake of ethanol (Walker \& Koob 2008; Walker et al., 2011; Philpot et al., 2003). This is most likely due to an up-regulation of the kappa opioid system resulting in increased responding for ethanol's negative reinforcing properties, with this effect being reversed by kappa opioid antagonists. Kappa opioid receptors are positioned pre-synaptically and tend to tonically inhibit dopamine release in the nucleus accumbens and in the prefrontal cortex via connections to the ventral tegmental area (see Sunil et al., 2012 for comprehensive review). Thus, changes in the function of this system (up-regulation) in dependent rats would explain their increased drinking and the effects of kappa opioid antagonism in these subjects. The above results are examples of a change in the endogenous opioid system due to experience with ethanol resulting in increased seeking and drinking of ethanol.

Experiments have shown changes in several opioid systems including the kappa opioid system after ethanol exposure in adulthood (Rosin et al., 1999; Turchan et al., 1999; Lindholm et al., 2000; Cowen \& Lawrence 2001; Zapata \& Shippenberg 2006; Sirohi et al., 2012). For example, Rosin and colleagues (1999) reported down regulation of kappa opioid receptor mRNA in the ventral tegmental area (VTA) and nucleus accumbens (NAc). On the other hand Lindholm et al., (2000) found an upregulation of Dynorphin-B in the NAc. These results suggest that the function of the kappa opioid system may change after chronic ethanol exposure during adulthood. We hypothesize that similar changes may occur after prenatal exposure to ethanol resulting in increased intake of and reinforcement to ethanol later in life, increasing the likelihood of alcohol dependence. This possibility is especially intriguing given kappa's ontogenetic change in motivational properties (from appetitive to aversive) during the $1^{\text {st }}$ and $2^{\text {nd }}$ postnatal weeks (Barr GA 1993; Petrov et al., 2006; Bals-Kubik et al., 1993; Varlinskaya et al., 1996). Specifically, Petrov et al., (2006) reported that newborn infant rats find kappa 
opioid receptor activation appetitive while adults have been shown to clearly find activation of kappa aversive.

The present study analyzed ethanol intake in preweanling rats following brief prenatal ethanol exposure during late gestation (Experiment 1). After establishing the reliability of increased ethanol intake following prenatal exposure to the drug, a subsequent experiment tested kappa opioid mediation of this phenomenon (Experiment 2). The possibility of prenatal ethanol affecting the motivational properties of both kappa and mu opioid signaling was then tested in Experiment 3 \& 4, via second order conditioned place preference (Pautassi et al., 2011; 2012).

\section{Methods}

\subsection{Subjects}

720 Sprague-Dawley male and female rat pups (postnatal day 14; PD14) representative of 90 litters, were employed in Experiments 1 through 5. The animals were PD14 at the start of the experimental procedures. All litters were born and reared at the Center for Development and Behavioral Neuroscience (Binghamton University, USA). Two females (at least PD60) were caged with a single male. For the following week vaginal smears were taken and the day of sperm detection was considered gestational day 0 (GD0). Births were examined daily and the day of parturition was considered as postnatal day 0 (PD 0). On PD1 litters were culled to 10 pups (5 males and 5 females, whenever possible). Pups were housed with the dam in standard maternity cages with free access to water and food. The colony was kept at $22-24^{\circ} \mathrm{C}$ and a 12-hour light-dark cycle was used with light onset occurring at 700 AM. All procedures were in compliance with the Guide for Care and Use of Laboratory Animals (National Institutes of Health, 1986) and were also approved by the Institutional Animal Care and Use Committee within an AAALAC-accredited facility. 


\subsection{Prenatal Ethanol Treatment}

The procedures were similar to those used in Fabio et al., (2013) and in DíazCenzano \& Chotro (2010). From gestational day 17 (GD17) to GD20 a randomly selected set of dams received daily intragastric (i.g) administrations of ethanol (12.6\% v/v ethanol solution; volume of administration: $0.01 \mathrm{ml} / \mathrm{g}$; dose: $1.0 \mathrm{~g} / \mathrm{kg}$ ); similar volume of vehicle (tap water), or remained untreated. Previous findings show this procedure results in fetuses achieving blood ethanol concentrations of approximately $50 \mathrm{mg} / \mathrm{dl}$ (Dominguez et al., 1998). Untreated dams were kept under similar housing conditions as the previous two groups but did not receive any treatment across GDs 17-20.

\subsection{Intraoral Cannulation}

Experiments 1 through 4 required cannulation for direct intraoral infusion of water or ethanol. A piece of polyethylene (PE)-10 tubing (Clay Adams, Parsippany, $\mathrm{NJ}$ ), $3 \mathrm{~cm}$ in length, was flanged at one end using a heat source. The non-flanged end of the tubing was tightly fit onto one end of a sharpened and curved stainless-steel wire $(0.285 \mathrm{~mm}$ diameter, approximately $4 \mathrm{~cm}$ in length). The wire was then inserted gently midline through the cheek, with the flanged tip resting anteriorly position on the interior portion of the cheek (Spear et al., 1989; Pautassi et al., 2002). The free end of the cannula was connected to PE-50 polyethylene tubing, which in turn was connected to a syringe placed in a 10-syringe infusion pump (KD Scientific, Holliston, MA). The size and schedule of the infusions was computer controlled. Unless stated otherwise, cannulation was performed $2 \mathrm{hr}$. prior to fluid infusion.

\subsection{Drug Preparation}


Norbinaltorphimine (nor-BNI: selective kappa opioid antagonist: Experiment 2), Spiradoline mesylate (U62,066E: selective kappa opioid agonist: Experiment 3), and Tyr-d-Ala-Gly-N-Me-Phe-Gly-ol enkephalin (DAMGO: selective mu opioid agonist: Experiment 4) (Sigma-Aldrich, St. Louis, MO) were administered via intraperitoneal (i.p.) injections, as described in Nizhnikov et al., (2006b). Briefly, 30 gauge needles were used, connected to $1 \mathrm{cc}$ tuberculin syringes. The site of the injection was located approximately halfway between the diaphragm and the genitalia, on the right side of the pup. Injections were executed in less than $10 \mathrm{~s}$. Injection volume was $0.01 \mathrm{ml} / \mathrm{g}$ for all doses and saline (0.9\%) was employed as the vehicle solution. Nor-BNI was administered 24 hours prior to the start of testing to allow for the drug effects to be selective for kappa opioid receptors (Metcalf and Coop, 2005).

\subsection{Infant Fluid Intake Test (Experiments 1 \& 2)}

The procedures were similar to those used in Chotro et al., (Chotro and Arias, 2006) and Pautassi et al., (2012b). Specifically, two hours prior to each days' intake test (Experiment 1: ethanol 5.0\%, 10.0\%, 20.0\% or water; Experiment 2: ethanol $5.0 \%$ or water), pups were removed from the dam, cannulated (described above), and placed in pairs ( 1 male and 1 female) in a heated holding chamber. Each pair of animals received the same type of fluid infusions so that ethanol animals were never with water animals. Following the 2 hour acclimation period pups were voided by gentle brushing of the anogenital region and weighed to the nearest $0.01 \mathrm{~g}$. Pups were given intraoral infusion of either ethanol or water (total volume: $5.5 \%$ of body weight, duration of infusion: 15 min) in warmed, individual clear plastic chambers $(8 \mathrm{~cm} \times 8 \mathrm{~cm} \times 25 \mathrm{~cm})$. Previous studies indicate that these infusion parameters allow subjects to ingest or reject the fluid delivered at will (Pautassi et al., 2002). At the end of the test, subjects were removed, dried, weighed, had their cannula removed, and either returned to their dams (Experiment 1) or to a warmed holding cage for 2 hours (Experiment 2). Following the 2 
hours the pups were returned to their dams overnight. Percent body weight gain of fluid ingested was calculated as follows: ((Pre-test Body Weight - Post-test Body Weight) / Pre-test Body Weight) * 100.

For Experiment 1 the test occurred on PD14 only. For Experiment 2 rat pups received a single i.p. injection with one of 3 doses of nor-BNI ( 0.0 (saline), $2.5 \mathrm{mg} / \mathrm{kg}$, or $10.0 \mathrm{mg} / \mathrm{kg}$ ) on PD13 and were then immediately returned to their dam for 24 hours. The intake procedure as described above was then performed for 5 consecutive days starting on PD14.

\subsection{Second-order conditioning and testing (Experiments $3 \& 4$ )}

Second-order conditioning (SOC), a variant of place conditioning, was conducted on postnatal days 14 (first-order conditioning) and 15 (test), as we have done previously (Pautassi et al., 2012b). SOC allows for the detection of ethanol's appetitive or aversive effects across all ages (Molina et al., 2006; Pautassi et al., 2008, 2011), as well as the pharmacological dissection of these effects (Pautassi et al., 2011; 2012b). The procedure was composed of three phases (first-order conditioning, second-order conditioning, and testing):

Phase 1 (first-order conditioning, PD 14): Pups were removed from their dam and placed in same-sex couples into a heated tub lined with pine shavings. Animals were immediately cannulated. A habituation phase was conducted $120 \mathrm{~min}$. later, to induce familiarization with the conditioning chambers. Animals were weighed and then placed for 10 min into square Plexiglas chambers $(10 \times 10 \times 12 \mathrm{~cm})$ lined with cotton. The preweanlings were then administered U62,066E (0.0, 1.0, 5.0 or $10.0 \mathrm{mg} / \mathrm{kg}$; Experiment 3) or DAMGO (0.0, 0.1, 1.0 or $5.0 \mathrm{mg} / \mathrm{kg}$; Experiment 4) and returned to their holding chambers. Conditioning started 5 or 30 minutes following the administration of U62,066E and DAMGO, respectively. The rationale for delaying conditioning with DAGMO up to 30 
minutes was to allow the peptide to cross the blood-brain barrier; prior studies indicate that DAMGO enters the brain, albeit slowly $[\mathrm{Kin}(\mu \mathrm{l} /(\mathrm{g} \times \mathrm{min})=0.40 \pm 0.55]$ (Van Dorpe et al., 2010). During the 15-min conditioning, which occurred in square Plexiglas chambers with cotton floors, the cheek PE-10 tubing was merged with the PE-50 tubing previously connected to an infusion pump (KD Scientific, Holliston, MA). The pump delivered the intraoral conditioned stimulus (CS1), which consisted of fifteen $5 \mathrm{~s}$ pulses ( $5 \mu \mathrm{l}$ per pulse; interstimulus interval: $55 \mathrm{~s}$ ) of distilled water. At termination of conditioning, the cheek cannula was removed and animals were placed into a warmed cage lined with wood shavings for $3 \mathrm{~h}$, allowing metabolic processing of the kappa and mu agonists before reunion with dam and the rest of their littermates.

Phase 2 (second-order conditioning, PD 15): Animals were cannulated and placed in a warmed cage for 60 min as we have previously done (Pautassi et al., 2012b). Second-order conditioning then began by placing the subjects into square chambers similar to those during Phase 1; however, the floor was covered with sandpaper (50 grit; Gatorgrit, Fairborn, $\mathrm{OH}$ ). The animals remained in these cages for four minutes and were given pairings of sandpaper (conditioned stimulus 2, CS2) and the distilled water CS1. Specifically, distilled water was intraorally infused every $55 \mathrm{~s}$ (volume: $5 \mu$; pulse duration: $5 \mathrm{~s}$ ) for 4 min.

Phase 3 (CPP test, PD 15): Thirty minutes after termination of Phase 2, animals were tested for CS2 preference in a two-way, 5 min tactile preference test. The test began by placing animals in a rectangular Plexiglas chamber ( 28

floor of the chamber was split in two halves. One half was lined with sandpaper CS2 (50 grit; Gatorgrit) and the other was lined with the smooth backside of a piece of sandpaper. Both textures were replaced after each test. Textures were selected based on previous experiments conducted in our lab that demonstrate their effectiveness in conditioning place preference experiments (e.g., Nizhnikov et al., 2009). An overhead 
40-watt red bulb illuminated the room and time spent in each section of the apparatus was manually recorded in 1 min bins by an experimenter blind to the conditioning treatment.

The intermediate section ( $15 \%$ of the entire surface) was considered a neutral area and not included for data gathering purposes. CS2 preference scores are expressed as the percent time spent on the rough sandpaper surface. Preference scores were calculated as follows: (total time spent over sandpaper) / (total time spent over sandpaper + total time spent over smooth) $\quad \square 100$.

\subsection{Tissue Collection and Western Blot Analysis.}

Two subjects (one male and one female) from each litter were not tested behaviorally but sacrificed via decapitation at PD14 and the brain was rapidly removed, flash frozen and stored at $-80^{\circ} \mathrm{C}$ until further use. The nucleus accumbens (nAc), hippocampus, amygdala (AMYG), and prefrontal cortex (PFC) were microdissected and assessed due to their involvement in addiction processes, memory, anxiety, impulse control, and drug reinstatement. Tissue was processed to determine receptor expression levels in P2 synaptosomal preparations as described elsewhere (Werner et al., 2011; Santerre et al., 2013). Briefly, tissue was homogenized in $320 \mathrm{mM}$ sucrose/phosphate buffered saline (PBS) solution and spun at low speed centrifugation $(1,000 \times \mathrm{g})$ and the subsequent supernatant was then spun again at $12,000 \times \mathrm{g}$ for $20 \mathrm{~min}$. The resulting pellet (P2) was resuspended in PBS. Protein concentrations were quantified using a bicinchoninic acid method. Protein samples were subjected to SDS-polyacrylamide gel electrophoresis using Novex Tris-Glycine (8-16\%) gels and transferred to polyvinylidene difluoride membranes (Invitrogen, Carlsbad, CA). Membranes were probed with a primary antibody for the kappa opioid receptor (Millipore, Billerica, MA) followed by appropriate secondary antibody (Thermo Scientific, Waltham, MA). Bands were detected using enhanced chemiluminescence (GE Healthcare, Amersham, UK) 
and exposed to autoradiographic film under nonsaturating conditions. All membranes were reexposed to $\beta$-actin to control for loading. Densitometric analysis was conducted using NIH Image J software. All samples were assessed in duplicate to triplicate.

\subsection{Research Design and Data analysis}

Significant main effects or interactions were examined through pair-wise post-hoc comparisons (Fisher's Least Mean Significant tests, alpha level set at 0.05). Experiment 1 assessed ethanol intake via a two way Analyses of Variance (ANOVA) and consisted of a 2 (sex) x 3 (Prenatal Treatment) x 4 (Ethanol concentrations) factorial design. Experiment 2 analyzed data via a repeated measures ANOVA and consisted of a 2 (sex) $\times 3$ (Prenatal Treatment) $\times 3$ (nor-BNI dose) design. Experiment 3 consisted of a 2 (sex) x 5 (U62,066 dose) design. Experiment 4 used a 2 (sex) x 5 (DAMGO dose) design. Both experiment 3 and 4 used a two way ANOVA to analyze results. Finally, Experiment 5 analyzed kappa opioid receptor expression following 2 prenatal treatments in 4 brain regions and utilized a Student's $t$-test to compare untreated and prenatally ethanol exposed subjects, since preliminary experiments indicated no differences in kappa opioid expression or ethanol intake between untreated and prenatally water exposed subjects in Experiment 1.

The dependent variables were ethanol and water intake (percent body weight gain, \%BWG; Experiments 1 and 2), and percent time spent over the sandpaper texture (Experiments 3 and 4). Kappa opioid receptor expression in specific brain regions was the dependent variable for Experiment 5.

In order to avoid overrepresentation of litters within each specific group, no more than 2 animals per litter (one male and one female) were assigned to each particular treatment. Sex was also considered as a factor; however, since this variable failed to 
exert significant main effects or interact with the remaining factors in all experiments, data were collapsed across this variable.

\section{Results}

\subsection{Experiment 1: Prenatal ethanol exposure increases subsequent ethanol intake.}

Experiment 1 assessed intake of several concentrations of ethanol or water in PD14 subjects as a function of prenatal treatment (percent body weight gain used as a measure of fluid intake). Analysis revealed main effects of fluid $F(3,88)=40.12, p<$ 0.0001 , and prenatal treatment $F(2,88)=3.89, p<0.05$, as well as a fluid $x$ prenatal treatment interaction $\mathrm{F}(6,88)=3.20, \mathrm{p}<0.01$. All subjects drank less $20 \%$ ethanol than any other fluid. However, animals experiencing prenatal ethanol drank more $5.0 \%$ ethanol than any other prenatal condition group, which did not differ from each other (Figure 1). No other differences in fluid intake were seen as a function of prenatal treatment. It seems that the prenatal ethanol exposure protocol used here, albeit much briefer than the one employed in other studies (e.g., Zhou et al., 2003), reliably promotes ethanol intake of a moderately (i.e., $5.0 \% \mathrm{v} / \mathrm{v}$ ) concentrated solution, without altering overall patterns of fluid intake.

[Insert Figure 1 about here]

3.2. Experiment 2: Kappa opioid receptor activity mediates ethanol intake in controls but not in animals prenatally exposed to ethanol.

In Experiment 2 the effects of nor-BNI pretreatment (kappa opioid antagonist) on intake of ethanol or water across 5 days was analyzed as a function of prenatal treatment. As $5 \%$ ethanol concentration elicited robust increases in ethanol intake following prenatal ethanol exposure, this concentration was used for Experiment 2. 
Preliminary analysis of animals injected with saline on PD13 revealed a main effect of prenatal treatment $(F(2,26)=11.48, p<0.001)$. Similar to Experiment 1 , Animals exposed to ethanol prenatally exhibited higher ethanol consumption than the remaining conditions. In view of these baseline differences in ethanol intake and following the statistical approach employed by Varlinskaya and Spear (2012), subsequent analyses were conducted separately based on prenatal treatment.

The ANOVA for prenatally untreated animals indicated a main effect of nor-BNI $F(2,100)=5.03, p<0.02$, days $F(4,100)=4.19, p<0.01$ and a nor-BNI $x$ testing day interaction $F(8,100)=2.61, p<0.02$. Further analysis indicated a slight, but significant, increase in ethanol intake on day 1 for animals given the $10 \mathrm{mg} / \mathrm{kg}$ nor-BNI dose (se Figure 2). Animals given both doses of nor-BNI exhibited significantly greater ethanol intake on days 4 and 5 than animals treated with $0.0 \mathrm{mg} / \mathrm{kg}$ nor-BNI.

For prenatally water treated animals, the analysis yielded a main effect of testing day $F(4,120)=9.70, p<0.0001 ;$ as well as a nor-BNI $x$ testing day interaction $F(8,120)=$ 2.07, $\mathrm{p}<0.05$. Further analysis indicated that the $2.5 \mathrm{mg} / \mathrm{kg}$ nor-BNI dose slightly, but significantly, increased ethanol intake on day 1 of testing. However, a more robust significant increase in ethanol intake following $2.5 \mathrm{mg} / \mathrm{kg}$ nor-BNI administration was seen on day 5 (Figure 3). A borderline effect was also observed for the $10 \mathrm{mg} / \mathrm{kg}$ dose at both days 1 and 5, but neither reached the level of significance.

The ANOVA for subjects treated prenatally with ethanol only revealed a main effect of testing day $(F(4,112)=7.07, p<0.0001)$. Ethanol intake was lower on day 2 than on any other test day and this pattern was similar in subjects given either dose of nor-BNI or vehicle (Figure 4).

Overall, the results from this experiment indicate that the antagonism of kappa opioid receptors results in increased ethanol intake in control animals, particularly after repeated exposure to ethanol. This effect may be due to an attenuation of the aversive 
effects of ethanol. Perhaps a more important result was that prenatal ethanol made animals insensitive to this kappa-mediation of ethanol intake.

[Insert Figure 2 about here]

3.3. Experiment 3: Changes in responding to kappa $(U 62,066)$ opioid stimulation as a function of prenatal ethanol exposure.

Analysis for time spent in contact with the sandpaper CS2 yielded a main effect of U62 treatment $(\mathrm{F} 4,188=2.63, \mathrm{p}<0.05)$ as well as a U62 treatment $x$ prenatal ethanol interaction $(F 8,188=2.56, p<0.05)$. Further analyses revealed that prenatal vehicle and prenatal untreated animals given the higher dose of the kappa agonist (10 mg/kg) spent less time on sandpaper than vehicle or untreated controls. This pattern of results, depicted in Figure 5, is indicative of U62-induced conditioned place avoidance. Furthermore, untreated animals also found the moderate dose of U62 $(5.0 \mathrm{mg} / \mathrm{kg})$ aversive. The post-hocs provided no indication of conditioned place avoidance in prenatally ethanol exposed pups. On the contrary, pups given ethanol in-utero and conditioned with $5 \mathrm{mg} / \mathrm{kg}$ U62 exhibited greater time spent on the sandpaper than untreated and vehicle-treated counterparts did.

This experiment indicates that prenatal ethanol may significantly alter the motivational tone of the endogenous kappa opioid system. Activation of this system induces, as expected, conditioned place avoidance in the offspring of control dams. Prenatal ethanol disrupted the expression of this conditioned avoidance and even made animals prefer the kappa-related texture, when the $5 \mathrm{mg} / \mathrm{kg}$ dose was employed.

3.4. Experiment 4: Changes in responding to mu (DAMGO) opioid stimulation as a function of prenatal ethanol exposure. 
Experiment 3 revealed that prenatal ethanol alters the sensitivity to the motivational consequences of KOR activation, an effect that may underlie the greater ethanol intake after prenatal exposure. Effects of prenatal exposure on the endogenous opioid system may be, however, broader, affecting functionality of mu receptors. Experiment 4 assessed second-order conditioned place preference/aversion, induced by the administration of the mu agonist DAMGO.

The ANOVA for percent time spent in the DAMO-related sandpaper, indicated the lack of significant main effects for prenatal exposure or DAMGO treatment. No significant interactions were observed (see Figure 6).

These results, taken together with those derived from Experiment 3, indicate that the effects of prenatal ethanol exposure, at this age, may be more dependent on changes on kappa than on mu opioid receptor function.

Insert Figures 3 and 4 about here

\subsection{Experiment 5: Changes in kappa opioid receptor expression as a function of prenatal ethanol exposure.}

Given the involvement of kappa opioid receptors in ethanol intake and the observed changes in preference for kappa opioid activation following prenatal ethanol exposure, we wanted to assess whether kappa opioid expression correlated with the behavioral responses. Compared to controls, we found that prenatal ethanol exposure reduced synaptosomal kappa opioid receptor expression in the nucleus accumbens by $41.6 \%(t=2.494, p<0.05$, Figure $7 A)$, as well as in the amygdala by $47.9 \%(t=2.606$, $p<0.05$, Figure 7B) and hippocampus by $52.5 \%(t=3.259, p<0.01$, Figure 7 C). No differences were found for the prefrontal cortex (Figure 7D). 
Insert Figure 5 about here

\subsection{Discussion:}

The current set of experiments tested the effects of brief prenatal exposure to physiologically relevant doses of ethanol during late gestation on ethanol intake, kappa opioid involvement in ethanol intake, and changes in kappa opioid function and expression.

The results indicate that relatively low prenatal ethanol exposure significantly increased drinking of $5.0 \%$ ethanol solution and decreased sensitivity to modulation of ethanol drinking by kappa opioid antagonists. Most strikingly, while control animals developed conditioned place aversions to textures paired with kappa agonists, experience with ethanol in the womb resulted in appetitive or neutral responding to kappa agonists. Changes in motivational responding after prenatal ethanol were specific to the kappa system, since no change was seen in response to a mu agonist.

Changes in preference for kappa opioid receptor activation were accompanied by a significant down regulation of kappa opioid receptor expression in brain regions critical for ethanol responding such as the nucleus accumbens, hippocampus, and amygdala. These results are especially intriguing since the specific brain areas affected by prenatal ethanol have been implicated in responding for ethanol. This set of results is consistent with previous work indicating that prenatal ethanol significantly enhances sensitivity to ethanol-induced appetitive effects, reduces sensitivity to ethanol-induced aversion (Pautassi et al., 2012a), and reduces baseline level of activation in the infralimbic area (Fabio et al., 2013).

Increased intake of ethanol following prenatal exposure has been shown in the past, and this effect lasts into adolescence (i.e., Diaz-Cenzano and Chotro, 2010; Fabio 
et al., 2013). However, a thorough analysis of acceptance of different concentrations following prenatal ethanol exposure has been lacking. Our findings indicate that prenatal exposure to $1.0 \mathrm{~g} / \mathrm{kg}$ ethanol during gestational days $17-20$ increases the intake of $5.0 \%$ but not $10.0 \%$ or $20.0 \%$ ethanol solution in PD14 rat pups (Experiment 1 ).

One possible reason for the increased intake is a change in the pharmacological reinforcing properties of ethanol following prenatal exposure. We have previously shown that animals experiencing ethanol prenatally find higher doses of ethanol reinforcing compared to controls (Nizhnikov et al., 2006a; Pautassi et al., 2012b). Similarly, in the present study changes in the reinforcing properties of a selective kappa agonist were attributed to prenatal ethanol. Control subjects found kappa opioid activation aversive, a result that was expected given that activation of the kappa opioid system has been shown to mediate the aversive properties of stress (Land et al., 2009) and that kappa agonists are aversive for adult animals (Mucha and Herz, 1985; Shippenberg and Herz, 1986; Bals-Kubik et al., 1989). Conversely, animals prenatally exposed to alcohol formed either preference for a texture paired with a kappa agonist or did not form an aversion (Experiment 3). This set of results suggests that prenatal ethanol induces a change in the function of the kappa opioid system.

The results of Experiment 4 with DAMGO were surprising given previous work showing conditioned place preference to central administration of this selective mu agonist (Bals-Kubik et al., 1993; Madhavan et al., 2010). However, differences in the route of administration, timing, and age of conditioning likely contribute to the differences between the above listed studies and ours. Alternatively, DAMGO may have affected the perception of the CS during the initial conditioning phase.

The kappa opioid system is of special interest with regard to prenatal ethanol exposure partly because of an established functional switch during normal ontogeny. In early infancy, activation of the kappa system is appetitive (Varlinskaya et al., 1996; 
Petrov et al., 2006), whereas later in development kappa agonists induce aversion (Mucha and Herz, 1985; Shippenberg and Herz, 1986; Bals-Kubik et al., 1989). Given the kappa system's established involvement in ethanol's aversive and dysphoric effects during late infancy and adulthood in non-dependent rats (Matsuzawa et al., 1999; Mitchell et al., 2005; Logrip et al., 2009), perturbation of this system during a particularly sensitive and critical developmental period may lead to changes in responding to alcohol later in life. Specifically, disruption of the kappa system may reduce the aversive properties of ethanol later in life, leading to increased propensity for use and abuse of ethanol. The present findings indicate that the switch in kappa opioid function (from appetitive to aversive) may be either delayed or reversed following prenatal ethanol exposure.

One possible explanation for the alteration in motivational sensitivity to kappa activation is that prenatal ethanol changes the expression of kappa opioid receptors in brain regions intimately related to ethanol responding. We found that kappa opioid receptor expression was decreased in the nucleus accumbens, amygdala, and hippocampus, but not the prefrontal cortex. Changes to opioid receptor expression following exposure to ethanol are not surprising in view of evidence that opioid peptides and receptors are altered following chronic alcohol exposure (Gianoulakis, 1996; Turchan et al., 1999; Chen and Lawrence, 2000; Lindholm et al., 2001). In fact, ethanol exposure has been shown to influence the kappa opioid system specifically. For example, Rosin et al., (1999) reported that chronic ethanol exposure up-regulates kappa mRNA levels. Such effects are also suggested by behavioral tests showing that a kappa opioid antagonist blocks increased ethanol intake only in alcohol-dependent animals (Walker and Koob, 2008). Taken together, these findings suggest an up-regulation of kappa opioid receptor expression due to prolonged ethanol exposure. 
In the present work, decreased kappa expression following low levels of ethanol exposure seems to contribute to increased ethanol intake. While the underlying mechanisms for these effects are not clear at present, the previously identified developmental switch in kappa opioid receptor function during early development may be involved. These effects may also depend upon dose and duration of ethanol exposure. Potentially, specific cellular mechanisms such as associations with $G$ proteins may underlie developmental and prenatal ethanol exposure effects. Furthermore, the persistence of reductions in kappa opioid function and expression needs to be investigated.

It is likely that trafficking of synaptosomal kappa opioid receptors also plays a major role in these effects of ethanol on the kappa opioid system, as has been shown for other receptors following ethanol exposure (reviewed in: Kumar et al., 2009). In particular, unpublished observations from our group indicate that total kappa opioid receptor expression in the nucleus accumbens following the same prenatal ethanol dose used here, albeit on prenatal day 12, displayed differences from controls. Although total expression needs to be further validated at the prenatal exposure age used here, together with the present results, this suggests that prenatal ethanol exposure might arrest synaptosomal trafficking mechanisms. Also, it is possible that the effects seen in this set of experiments persists into adolescence or even adulthood. Nonetheless, this is the first time that prenatal exposure at such low, albeit physiologically relevant, ethanol levels have been shown to exert such profound effects on kappa opioid function and expression.

While the current work focuses on the contributions of kappa opioid receptors, other opioid systems should also be assessed and contributions of non-opioid systems such as GABA and glutamate should be explored in the present context. While the limbic system has been a major focus, we cannot rule out changes in ethanol taste preference, 
as previous results indicate increased ethanol palatability following prenatal ethanol exposure (Arias and Chotro, 2005; Youngentob and Glendinning, 2009; Glendinning et al., 2012).

Our previous work indicates that the doses used in the present studies do not produce changes in placenta weight, umbilical cord length, offspring's body weights, weights and/or size of the olfactory bulbs, cerebral hemispheres, and cerebellum or the granular layer of the olfactory bulb (Dominguez et al., 1998; Pueta et al., 2011). However, we cannot rule out that these low levels of prenatal ethanol exposure may produce other molecular teratological effects. Alternatively, these animals could have experienced difficulty learning. However, such a possibility is unlikely, given previous evidence that the present prenatal ethanol treatment does not preclude learning (Nizhnikov et al., 2006a; Pautassi et al., 2012b). Additionally, the animals in the present study readily displayed learned preference for a texture paired with a kappa agonist and were therefore capable of conditioning.

In conclusion, the results presented here add to a growing literature indicating increased ethanol intake following prenatal ethanol exposure (see: Spear and Molina, 2005) and highlight limbic kappa opioid receptor involvement in the effects of prenatal ethanol exposure on ethanol intake later in life.

\section{REFERENCES:}

Alati R, Al Mamun A, Williams GM, O'Callaghan M, Najman JM, Bor W (2006) In utero alcohol exposure and prediction of alcohol disorders in early adulthood: a birth cohort study. Arch Gen Psychiatry 63:1009-1016.

Alati R, Clavarino A, Najman JM, O'Callaghan M, Bor W, Mamun AA, Williams GM (2008) The developmental origin of adolescent alcohol use: findings from the 
Mater University Study of Pregnancy and its outcomes. Drug and alcohol dependence 98:136-143.

Arias C, Chotro MG (2005) Increased preference for ethanol in the infant rat after prenatal ethanol exposure, expressed on intake and taste reactivity tests. Alcohol Clin Exp Res 29:337-346.

Baer JS, Barr HM, Bookstein FL, Sampson PD, Streissguth AP (1998) Prenatal alcohol exposure and family history of alcoholism in the etiology of adolescent alcohol problems. J Stud Alcohol 59:533-543.

Baer JS, Sampson PD, Barr HM, Connor PD, Streissguth AP (2003) A 21-year longitudinal analysis of the effects of prenatal alcohol exposure on young adult drinking. Arch Gen Psychiatry 60:377-385.

Bals-Kubik R, Herz A, Shippenberg TS (1989) Evidence that the aversive effects of opioid antagonists and kappa-agonists are centrally mediated. Psychopharmacology (Berl) 98:203-206.

Bals-Kubik R, Ableitner A, Herz A, Shippenberg TS (1993) Neuroanatomical sites mediating the motivational effects of opioids as mapped by the conditioned place preference paradigm in rats. J Pharmacol Exp Ther 264:489-495.

Barson JR, Carr AJ, Soun JE, Sobhani NC, Rada P, Leibowitz SF, Hoebel BG (2010) Opioids in the hypothalamic paraventricular nucleus stimulate ethanol intake. Alcohol Clin Exp Res 34:214-222.

Chen F, Lawrence AJ (2000) Effect of chronic ethanol and withdrawal on the mu-opioid receptor- and 5-Hydroxytryptamine(1A) receptor-stimulated binding of 
[(35)S]Guanosine-5'-O-(3-thio)triphosphate in the fawn-hooded rat brain: A quantitative autoradiography study. J Pharmacol Exp Ther 293:159-165.

Chotro MG, Arias C (2006) Exposure to low and moderate doses of alcohol on late gestation modifies infantile response to and preference for alcohol in rats. Annali dell'Istituto superiore di sanita 42:22-30.

Cowen MS, Lawrence AJ (2001) Alterations in central preproenkephalin mRNA expression after chronic free-choice ethanol consumption by fawn-hooded rats. Alcohol Clin Exp Res 25:1126-1133.

Diaz-Cenzano E, Chotro MG (2010) Prenatal binge ethanol exposure on gestation days 19-20, but not on days 17-18, increases postnatal ethanol acceptance in rats. Behav Neurosci 124:362-369.

Dominguez HD, Lopez MF, Molina JC (1998) Neonatal responsiveness to alcohol odor and infant alcohol intake as a function of alcohol experience during late gestation. Alcohol 16:109-117.

Eade AM, Youngentob SL (2010) The interaction of gestational and postnatal ethanol experience on the adolescent and adult odor-mediated responses to ethanol in observer and demonstrator rats. Alcohol Clin Exp Res 34:1705-1713.

Fabio MC, March SM, Molina JC, Nizhnikov ME, Spear NE, Pautassi RM (2013) Prenatal ethanol exposure increases ethanol intake and reduces C-fos expression in infralimbic cortex of adolescent rats. Pharmacol Biochem Behav 103:842-852. Gianoulakis C (1996) Implications of endogenous opioids and dopamine in alcoholism: human and basic science studies. Alcohol Alcohol Suppl 1:33-42. 
Glendinning JI, Simons YM, Youngentob L, Youngentob SL (2012) Fetal ethanol exposure attenuates aversive oral effects of TrpV1, but not TrpA1 agonists in rats. Exp Biol Med (Maywood) 237:236-240.

Kato H (2008) [Pharmacological effects of a mu-opioid receptor antagonist naltrexone on alcohol dependence]. Nihon Arukoru Yakubutsu Igakkai zasshi = Japanese journal of alcohol studies \& drug dependence 43:697-704.

Kumar S, Porcu P, Werner DF, Matthews DB, Diaz-Granados JL, Helfand RS, Morrow AL (2009) The role of GABA(A) receptors in the acute and chronic effects of ethanol: a decade of progress. Psychopharmacology (Berl) 205:529-564.

Land BB, Bruchas MR, Schattauer S, Giardino WJ, Aita M, Messinger D, Hnasko TS, Palmiter RD, Chavkin C (2009) Activation of the kappa opioid receptor in the dorsal raphe nucleus mediates the aversive effects of stress and reinstates drug seeking. Proc Natl Acad Sci U S A 106:19168-19173.

Lindholm S, Werme M, Brene S, Franck J (2001) The selective kappa-opioid receptor agonist U50,488H attenuates voluntary ethanol intake in the rat. Behav Brain Res 120:137-146.

Logrip ML, Janak PH, Ron D (2009) Blockade of ethanol reward by the kappa opioid receptor agonist U50,488H. Alcohol 43:359-365.

Madhavan A, Bonci A, Whistler JL (2010) Opioid-Induced GABA potentiation after chronic morphine attenuates the rewarding effects of opioids in the ventral tegmental area. J Neurosci 30:14029-14035. 
Matsuzawa S, Suzuki T, Misawa M, Nagase H (1999) Different roles of mu-, delta- and kappa-opioid receptors in ethanol-associated place preference in rats exposed to conditioned fear stress. Eur J Pharmacol 368:9-16.

Mendez M, Morales-Mulia M (2008) Role of mu and delta opioid receptors in alcohol drinking behaviour. Current drug abuse reviews 1:239-252.

Metcalf MD, Coop A (2005) Kappa opioid antagonists: past successes and future prospects. The AAPS journal 7:E704-722.

Mitchell JM, Liang MT, Fields HL (2005) A single injection of the kappa opioid antagonist norbinaltorphimine increases ethanol consumption in rats. Psychopharmacology (Berl) 182:384-392.

Molina JC, Ponce LF, Truxell E, Spear NE (2006) Infantile sensitivity to ethanol's motivational effects: Ethanol reinforcement during the third postnatal week. Alcohol Clin Exp Res 30:1506-1519.

Mucha RF, Herz A (1985) Motivational properties of kappa and mu opioid receptor agonists studied with place and taste preference conditioning. Psychopharmacology (Berl) 86:274-280.

Nizhnikov ME, Molina JC, Varlinskaya EI, Spear NE (2006a) Prenatal ethanol exposure increases ethanol reinforcement in neonatal rats. Alcohol Clin Exp Res 30:34-45. Nizhnikov ME, Varlinskaya EI, Petrov ES, Spear NE (2006b) Reinforcing properties of ethanol in neonatal rats: involvement of the opioid system. Behav Neurosci 120:267-280. 
Nizhnikov ME, Pautassi RM, Truxell E, Spear NE (2009) Opioid antagonists block the acquisition of ethanol-mediated conditioned tactile preference in infant rats. Alcohol 43:347-358.

Pautassi RM, Godoy JC, Spear NE, Molina JC (2002) Early responsiveness to stimuli paired with different stages within the state of alcohol intoxication. Alcohol Clin Exp Res 26:644-654.

Pautassi RM, Nizhnikov ME, Acevedo MB, Spear NE (2012a) Early role of the kappa opioid receptor in ethanol-induced reinforcement. Physiol Behav 105:1231-1241.

Pautassi RM, Nizhnikov ME, Spear NE, Molina JC (2012b) Prenatal ethanol exposure leads to greater ethanol-induced appetitive reinforcement. Alcohol 46:585-593.

Pautassi RM, Myers M, Spear LP, Molina JC, Spear NE (2008) Adolescent but not adult rats exhibit ethanol-mediated appetitive second-order conditioning. Alcohol Clin Exp Res 32:2016-2027.

Pautassi RM, Myers M, Spear LP, Molina JC, Spear NE (2011) Ethanol induces secondorder aversive conditioning in adolescent and adult rats. Alcohol 45:45-55.

Petrov ES, Nizhnikov ME, Varlinskaya EI, Spear NE (2006) Dynorphin A (1-13) and responsiveness of the newborn rat to a surrogate nipple: immediate behavioral consequences and reinforcement effects in conditioning. Behav Brain Res 170:114.

Pettinati HM, O'Brien CP, Rabinowitz AR, Wortman SP, Oslin DW, Kampman KM, Dackis CA (2006) The status of naltrexone in the treatment of alcohol dependence: specific effects on heavy drinking. Journal of clinical psychopharmacology 26:610-625. 
Pueta M, Rovasio RA, Abate P, Spear NE, Molina JC (2011) Prenatal and postnatal ethanol experiences modulate consumption of the drug in rat pups, without impairment in the granular cell layer of the main olfactory bulb. Physiol Behav 102:63-75.

Rosin A, Lindholm S, Franck J, Georgieva J (1999) Downregulation of kappa opioid receptor mRNA levels by chronic ethanol and repetitive cocaine in rat ventral tegmentum and nucleus accumbens. Neurosci Lett 275:1-4.

Santerre JL, Gigante ED, Landin JD, Werner DF (2013) Molecular and behavioral characterization of adolescen protein kinase $\mathrm{C}$ following high dose ethanol exposure. Psychopharmacology (Berl) In Press.

Shippenberg TS, Herz A (1986) Differential effects of mu and kappa opioid systems on motivational processes. NIDA research monograph 75:563-566.

Sommer W, Hyytia P, Kiianmaa K (2006) The alcohol-preferring AA and alcoholavoiding ANA rats: neurobiology of the regulation of alcohol drinking. Addict Biol 11:289-309.

Spear LP, Specht SM, Kirstein CL, Kuhn CM (1989) Anterior and posterior, but not cheek, intraoral cannulation procedures elevate serum corticosterone levels in neonatal rat pups. Developmental psychobiology 22:401-411.

Spear NE, Molina JC (2005) Fetal or infantile exposure to ethanol promotes ethanol ingestion in adolescence and adulthood: a theoretical review. Alcohol Clin Exp Res 29:909-929.

Turchan J, Przewlocka B, Toth G, Lason W, Borsodi A, Przewlocki R (1999) The effect of repeated administration of morphine, cocaine and ethanol on mu and delta 
opioid receptor density in the nucleus accumbens and striatum of the rat.

Neuroscience 91:971-977.

Van Dorpe S, Adriaens A, Polis I, Peremans K, Van Bocxlaer J, De Spiegeleer B (2010)

Analytical characterization and comparison of the blood-brain barrier permeability of eight opioid peptides. Peptides 31:1390-1399.

Varlinskaya EI, Petrov ES, Smotherman WP (1996) Classical conditioning in the fetal rat: reinforcing properties of dynorphin A (1-13). Behav Neurosci 110:154-167.

Walker BM, Koob GF (2008) Pharmacological evidence for a motivational role of kappaopioid systems in ethanol dependence. Neuropsychopharmacology 33:643-652.

Werner DF, Kumar S, Criswell HE, Suryanarayanan A, Fetzer JA, Comerford CE, Morrow AL (2011) PKCgamma is required for ethanol-induced increases in GABA(A) receptor alpha4 subunit expression in cultured cerebral cortical neurons. J Neurochem 116:554-563.

Youngentob SL, Glendinning JI (2009) Fetal ethanol exposure increases ethanol intake by making it smell and taste better. Proc Natl Acad Sci U S A 106:5359-5364.

Zapata A, Shippenberg TS (2006) Endogenous kappa opioid receptor systems modulate the responsiveness of mesoaccumbal dopamine neurons to ethanol. Alcohol Clin Exp Res 30:592-597.

Atalli B, Saya D, Vogen Z (1990) Pre-and postnatal development of opiate recaeptor subtypes in rat spinal cord. Brain Res 53: 97-102.

Leslie FM, Loughlin, SE (1992) Development of multiple opioid receptors. In Miller MW (ed), Development of the Central Nervous System: Effects of Alcohol and Opiates. NY: Wiley-Liss, 255. 
Leslie ML, Loughlin SE (1993). Ontogeny and plasticity of opioid systems. In Hammer RP. (Eds.), The Neurobiology of Opiates (pp. 85-123). Boca Raton, FL, USA: CRC Press, Inc. 408 pp.

Petrillo P, Tavani A, Verotta D, Robson LE, Kosterlitz HW (1987) Differential postnatal development of mu-, delta- and kappa-opioid binding sites in rat brain. Brain Res 428: 53-58.

Fabio MC, March SM, Molina JC, Nizhnikov ME, Spear NE, Pautassi RM. (2013) Prenatal ethanol exposure increases ethanol intake and reduces $\mathrm{C}$-fos expression in infralimbic cortex of adolescent rats. Pharmacol Biochem Behav. 103(4):842-52.

Abate P, Varlinskaya El, Cheslock SJ, Spear NE, Molina JC. (2002). Neonatal activation of alcohol-related prenatal memories: impact on the first suckling response. Alcohol Clin Exp Res. 26(10):1512-22.

Abate P, Pepino MY, Spear NE, Molina JC. (2004). Fetal learning with ethanol: correlations between maternal hypothermia during pregnancy and neonatal responsiveness to chemosensory cues of the drug. Alcohol Clin Exp Res. 28(5):805-15.

Miranda-Morales RS, Molina JC, Spear NE, Abate P. (2010). Participation of the endogenous opioid system in the acquisition of a prenatal ethanol-related memory: effects on neonatal and preweanling responsiveness to ethanol. Physiol Behav. 4;101(1):153-60.

Zhou FC, Sari Y, Powrozek T, Goodlett CR, Li TK. (2003). Moderate alcohol exposure compromises neural tube midline development in prenatal brain. Brain Res Dev Brain 144(1):43-55.

Zhou FC, Sari Y, Powrozek T, Goodlett CR, Li TK. (2003). Moderate alcohol exposure compromises neural tube midline development in prenatal brain. Brain Res Dev Brain Res. 144(1):43-55.

Varlinskaya El, Spear LP. (2012). Increases in anxiety-like behavior induced by acute stress are reversed by ethanol in adolescent but not adult rats. Pharmacol Biochem Behav. 100(3):440-50. 


\section{Figure Captions:}

Figure 1. Drinking of several concentrations of ethanol (percentage of body weight gain, $\%$ BWG $)$ as a function of prenatal ethanol treatment $(0.0,1.0 \mathrm{~g} / \mathrm{kg}$ or no treatment $)$ is presented. Vertical bars depict means \pm S.E.M. The results indicate a significant increase in drinking of $5.0 \%$ ethanol in subjects exposed to ethanol prenatally compared to controls $(F(2,88)=3.89, p<0.05)$. Asterisk indicates a significant difference in a given group from water controls.

Figure 2. Drinking of 5.0\% ethanol (percentage of body weight gain, \% BWG) as a function of pretreatment with a kappa opioid antagonist (nor-BNI) in pups derived from untreated (panel A), prenatally water (panel B), or prenatally ethanol (panel C) treated dams across 5 days of testing is depicted as means \pm S.E.M. The kappa opioid antagonist nor-BNI was given 24 hours prior to testing). The results indicate a significant increase in ethanol intake in prenatally untreated subjects for subjects receiving the high dose of nor-BNI on day 1 and both doses on days 4 and $5(F(2,100)=5.03, p<0.02)$. Analysis for prenatally water treated animals indicated that the $2.5 \mathrm{mg} / \mathrm{kg}$ nor-BNI dose slightly, but significantly, increased ethanol intake on day 1 of testing. However, a more robust significant increase in ethanol intake following $2.5 \mathrm{mg} / \mathrm{kg}$ nor-BNI administration was seen on day $5, F(8,120)=2.07, p<0.05$. For prenatally ethanol treated subjects no effect of nor-BNI was seen. Asterisk indicates a significant difference from water controls.

Figure 3. Percent time spent on a conditioned stimulus (CS+, a sandpaper texture) associated with the effects of a kappa opioid agonist (U62,066E), as a function of prenatal treatment $(0.0,1.0 \mathrm{~g} / \mathrm{kg}$ ethanol, or no treatment) and U62,066E dose $(0.0,1.0$, 5.0 or $10.0 \mathrm{mg} / \mathrm{kg}$; or untreated). The results indicate a significant drug x prenatal 
treatment interaction $(F(4,188)=2.63, p<0.05)$. Control subjects (untreated, prenatal water) displayed aversion to the effects of 5.0 or $10.0 \mathrm{mg} / \mathrm{kg}$ U62,066E, while prenatally ethanol treated pups showed no aversion and even preference for the $5.0 \mathrm{mg} / \mathrm{kg}$ dose. Percent time spent in the CS+ is depicted as means \pm S.E.M.

Figure 4. Percent time spent on a conditioned stimulus (CS+, a sandpaper texture) associated with the effects of a mu opioid agonist (DAMGO), as a function of prenatal treatment $(0.0,1.0 \mathrm{~g} / \mathrm{kg}$ or no treatment) and DAMGO dose $(0.0,0.1,1.0$ or $5.0 \mathrm{mg} / \mathrm{kg}$; or untreated). The results indicate no significant main effects or interactions. Percent time spent on the CS+ is depicted as means \pm S.E.M.

Figure 5. Synaptosomal kappa opioid expression following prenatal ethanol exposure in the nucleus accumbens (NAc) (A), amygdala (B), hippocampus (C), and prefrontal cortex (PFC) (D). The results indicate that prenatal ethanol exposure reduced synaptosomal kappa opioid expression $41-52 \%$ in the nucleus accumbens, amygdala and hippocampus. The prefrontal cortex was unaffected. Representative blots are shown for each region. Data is presented as mean \pm S.E.M. * $p<0.05, n=5-8$ per group. 


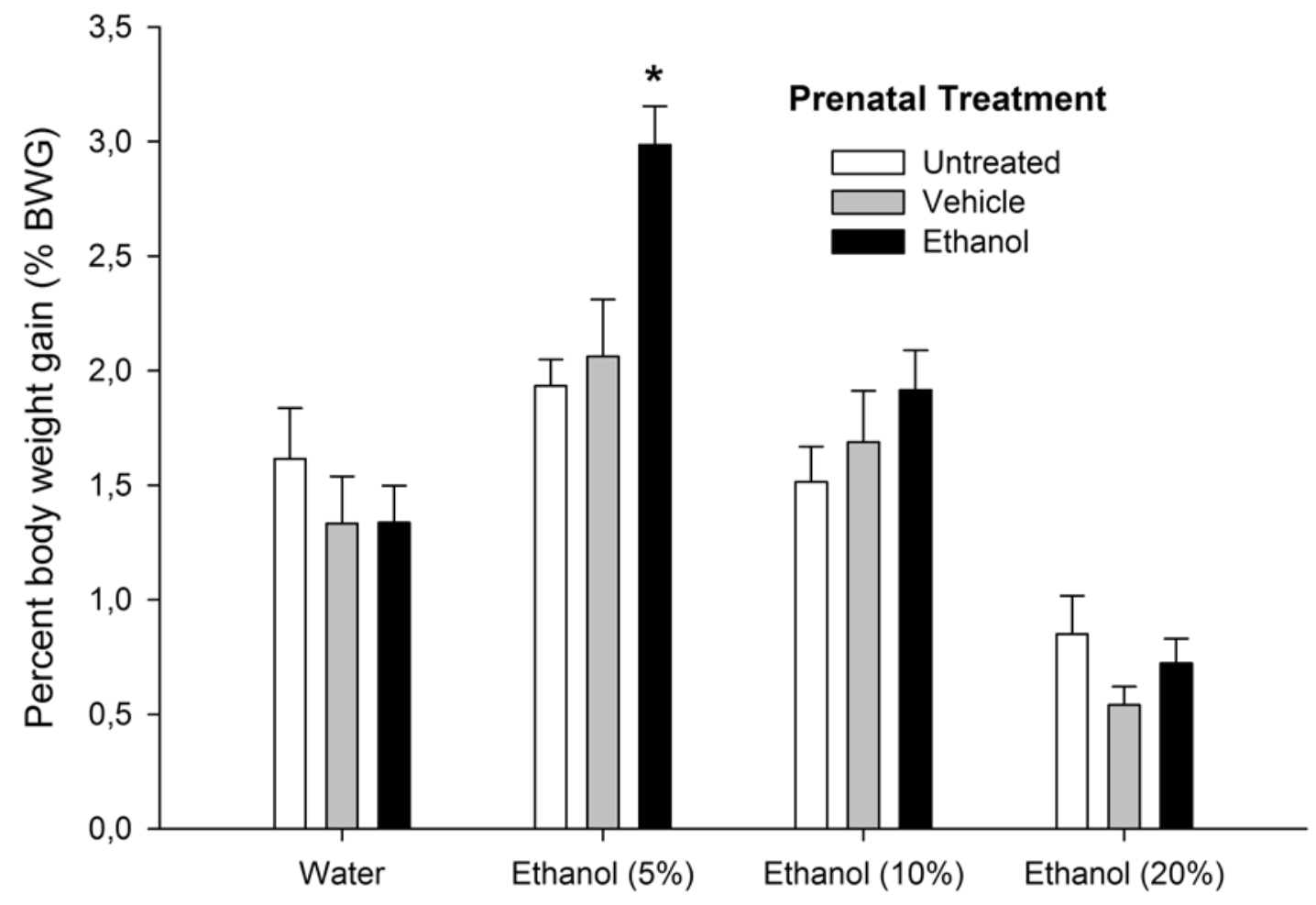

Fluid at test

Figure1 

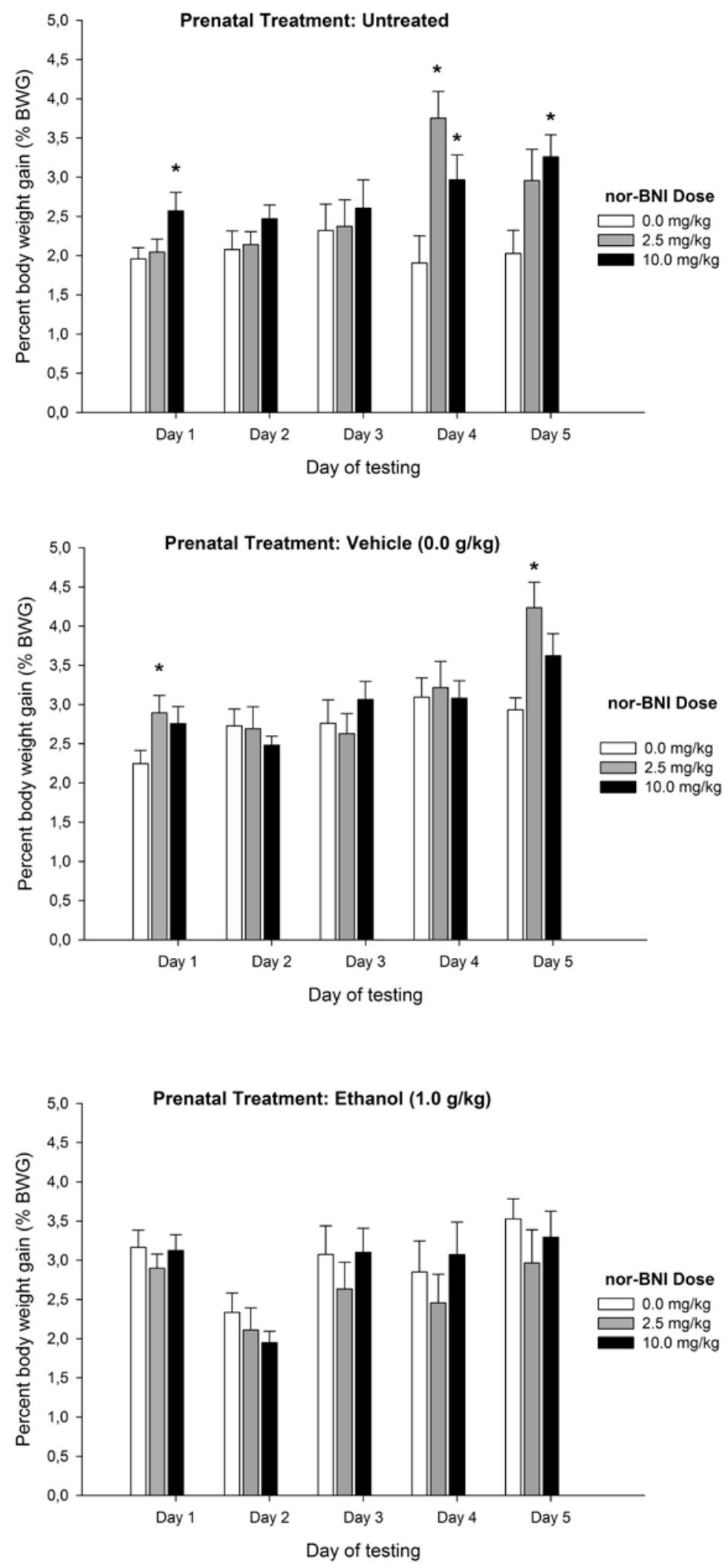

Figure2 
Figure3

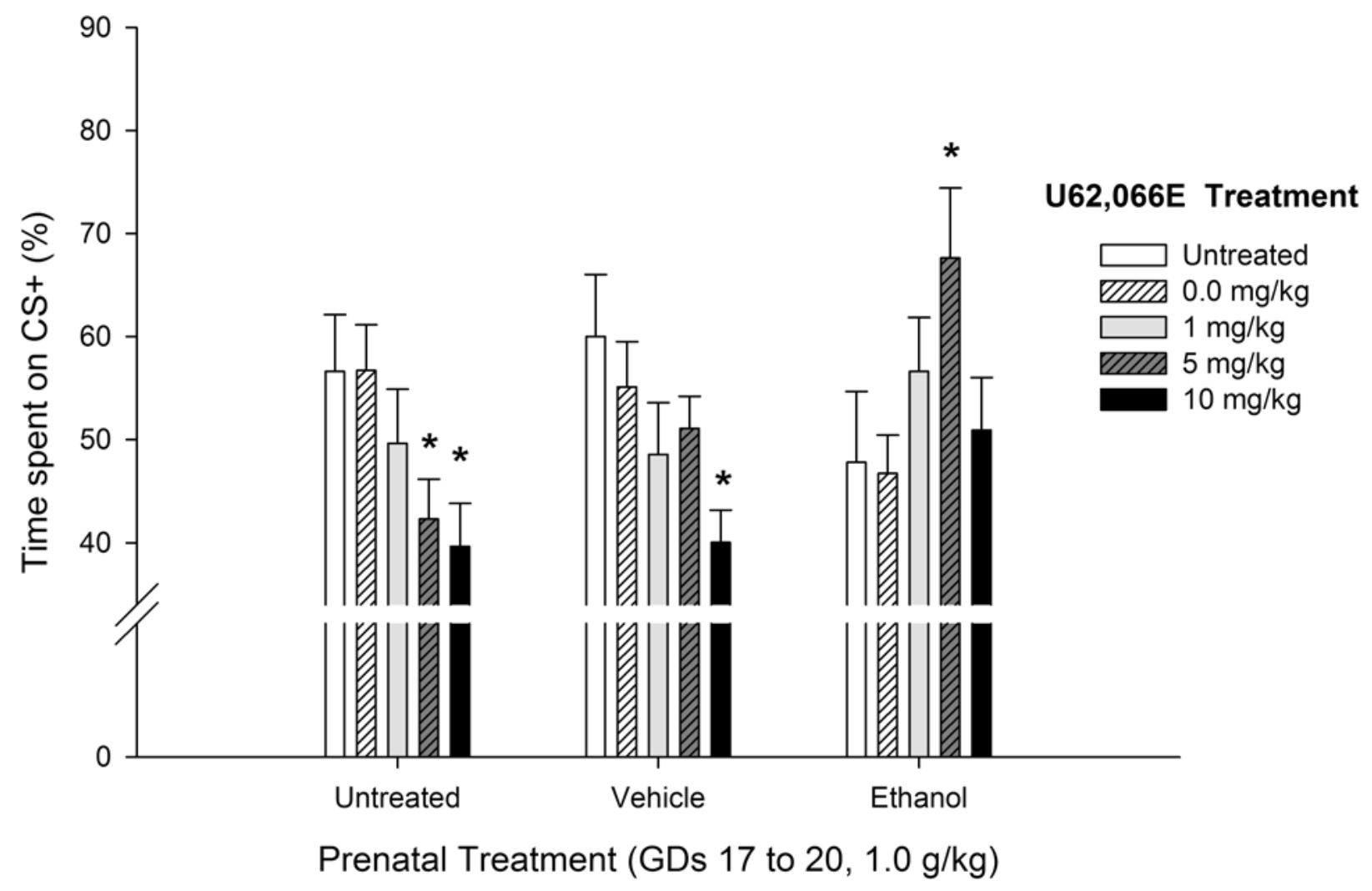


Figure 4




